\title{
Improvement of Gums in Physicochemical and Rheological Properties of Barley-fortified Saltine Cracker Dough
}

\author{
J. LI ${ }^{1,2}$, G.G. Hou ${ }^{3}$ and Z.X. CHEN ${ }^{2 *}$ \\ ${ }^{1}$ State Key Laboratory of Food Science and Technology, School of Food Science and Technology, \\ Jiangnan University, Wuxi, Jiangsu 214122, PR China \\ ${ }^{2}$ National Engineering Laboratory for Cereal Fermentation Technology, Jiangnan University, Wuxi, \\ Jiangsu 214122, PR China \\ ${ }^{3}$ Wheat Marketing Center, 1200 NW Naito Parkway, Suite 230, Portland, OR 97209, USA
}

(Received 18 November 2015; Accepted 19 January 2016;

Communicated by F. Békés)

\begin{abstract}
Effects of hydrocolloids (arabic gum, guar gum, and xanthan gum) on the physicochemical and rheological properties of whole-barley fortified cracker flour were determined using solvent retention capacity, alveograph, and Mixolab profiles. Results showed that the water absorption of whole-barley fortified cracker flour was reduced by the additional arabic gum. Besides, arabic gum was more effective in reducing the resistance to inflation and improving the extensibility of whole-barley fortified dough. Mixolab parameters indicated that the weakening of gluten proteins and the rate of starch retrogradation in whole-barley fortified cracker dough were reduced by the presence of arabic gum. Guar gum and xanthan gum promoted the rate of protein breakdown, but slowed down the starch gelatinization and retrogradation rate during the Mixolab heating-cooling cycle. In conclusion, involved arabic gum rather than guar gum or xanthan gum is benefit to improve the baking quality of wholebarley fortified saltine crackers.
\end{abstract}

Keywords: gums, barley, rheological properties, Mixolab

\section{Introduction}

Barley ranks the fourth in cereal grain production worldwide, and is predominately used in brewing and for animal feed. Barley is rich in dietary fiber, vitamins, minerals, antioxidants, tocotrienols, phenolic acids, and flavonoids, but is low in saturated fat and sodium (Slavin et al. 2000).

High fiber (both soluble and insoluble fiber) content of barley flour yields high water absorption capacity due to the polysaccharides' structure (Izydorczyk et al. 1998). In the production of barley-fortified cracker, some processing difficulties are experienced due to high water absorption of whole-barley flour, combined with low weak gluten strength and stickiness of whole-barley dough. Additional water is required during the preparation of barley-fortified cracker dough for optimum dough formation and processing. Crackers

*Corresponding author; E-mail: zxchen2006@126.com; Phone/Fax: +86 051085326012 
are low-moisture content (about $3 \sim 4 \%$ of the final products) to get a crispy texture. However, increased amount of water in whole-barley fortified cracker dough led to increase the baking time and temperature to meet the moisture content of finished product.

Hydrocolloids are comprised by a number of water-soluble polysaccharides with different chemical structure providing a range of functional properties (Rosell et al. 2007).

Hydrocolloids could modify gluten and starch properties by affecting the hydration properties of gluten and altering the gelatinization and retrogradation behaviors of starch (Bárcenasb et al. 2009). Studies showed that hydrocolloids exhibited various effects on starch gelatinization and retrogradation, and their functions were highly dependent on molecular structure, environmental conditions and concentration (Rosell et al. 2001). Our previous research indicated that the involved arabic gum had a positive effect on the quality of whole-wheat saltine cracker including reduced water absorption of whole-grain flour, increased dough extensibility, and improved dough handling and machinability (Li et al. 2013).

Solvent retention capacity (SRC) profiles and alveograph have been routinely used to evaluate the performance of soft wheat flour for cookie and cracker products (Kweon et al. 2011; Li et al. 2014), and Mixolab is showing a predicting tool for similar purpose (Stoenescu et al. 2010). Therefore, the objective of this research was to examine the effects of three hydrocolloids (arabic gum, guar gum and xanthan gum) commonly employed in food product formulations on the physicochemical and rheological properties of whole-barley fortified cracker dough.

\section{Materials and Methods}

\section{Materials}

Whole-barley fortified saltine cracker flour samples were composited from blends of whole-barley flour (WB), soft red winter (SRW), and hard red winter (HRW) flour. WB (Giusto's ${ }^{\circledR}$ : $10.5 \%$ protein, $11.0 \%$ moisture, $1.25 \%$ ash) was purchased from Giusto's Specialty Foods Company (CA, USA). SRW (Golden Shield, enriched and unbleached) and HRW (Harvest King ${ }^{\circledR}$ hard red winter flour, enriched and unbleached) were obtained from General Mills, Inc. (Minneapolis, MN, USA). Pre-Hydrated ${ }^{\circledR}$ gum Arabic-FT (arabic gum), Pretested ${ }^{\circledR}$ Colloid FLOD’N FLEX Powder (guar gum), and Ticaxan ${ }^{\circledR}$ Xanthan 200EC (xanthan gum) were kindly offered by the TIC gums, Inc. (Belcamp, MD, USA).

\section{Whole-barley fortified cracker flour preparation}

Different addition levels $(0.5 \%, 1.0 \%$, and $2.0 \%)$ of three gums (w/w, based on flour weight) and different levels $(0 \%, 25 \%, 50 \%$, and $75 \%)$ of whole-barley flour, HRW $(15 \%)$ and SRW flour (the balance amount) were mixed for $20 \mathrm{~min}$ to homogeneity in a blender (model 71, IMER International Inc., Poggibonsi, Italy). 


\section{Solvent Retention Capacity (SRC)}

Four diagnostic solvents as lactic acid SRC (LA-SRC), sodium carbonate SRC (SC-SRC), sucrose SRC (Suc-SRC), and water SRC were tested according to the AACC International Approved Method 56-11.02.

\section{Alveograph}

The alveograph $(\mathrm{P}, \mathrm{L}, \mathrm{W}$, and $\mathrm{P} / \mathrm{L})$ values of whole-barley fortified flour blends added with different levels of each gum were tested according to the AACC International Approved Method 54-30.02.

\section{Mixolab}

The mixing and pasting behaviors of whole-barley fortified flour blends added with different hydrocolloids (arabic gum, guar gum, and xanthan gum) at $2.0 \%$ level were determined using the Mixolab (Chopin Technologies, Villeneuve La Garenne, France). For the Mixolab trial, each of the whole-barley fortified dough samples (75 g) was mixed in the mixing bowl to produce a torque of $1.1 \mathrm{Nm}$. A typical Mixolab curve is divided into five different stages (Fig. 1).

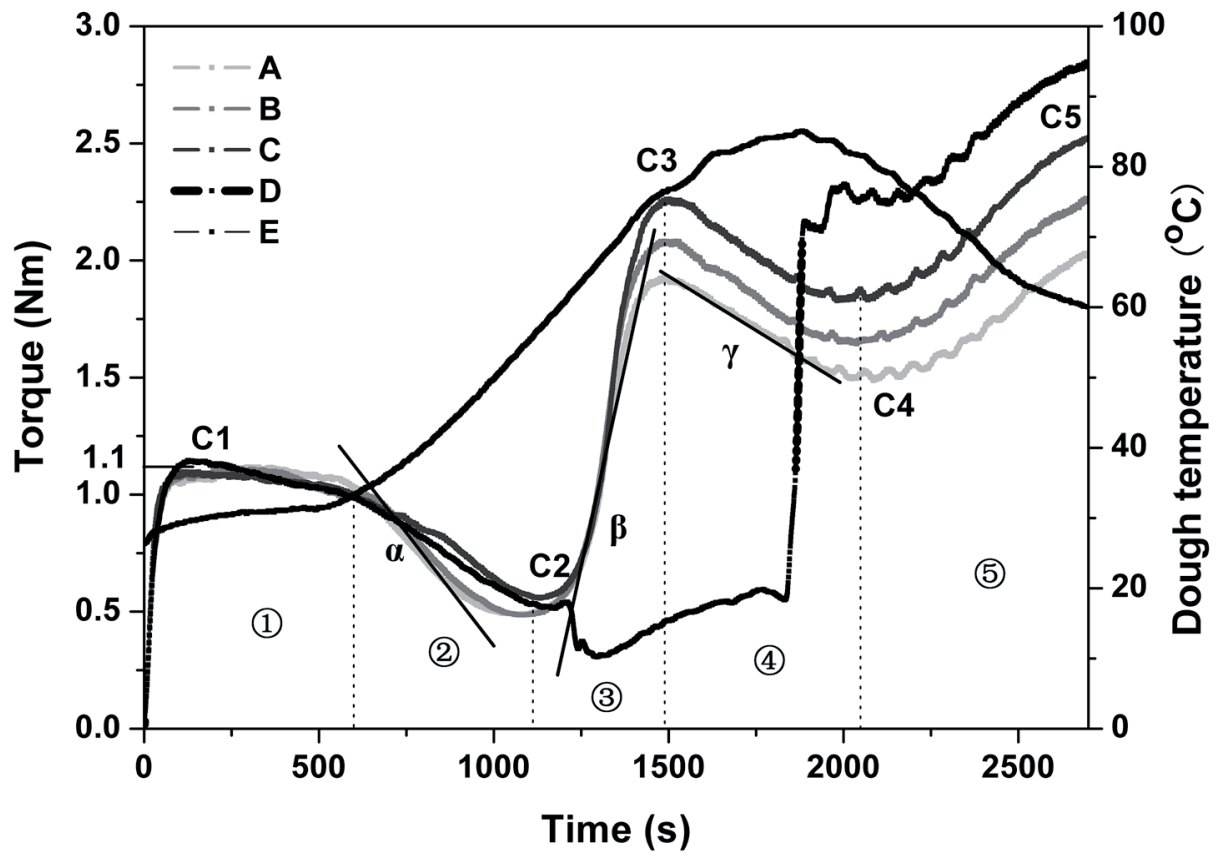

Figure 1. Typical Mixolab curves of whole-barley fortified flour blends. A) 25\% whole-barley fortified flour blends; B) $50 \%$ whole-barley fortified flour blends; C) $75 \%$ whole-barley fortified flour blends; D) $100 \%$ whole-barley flour; E) dough temperature 


\begin{tabular}{|c|c|c|c|c|c|c|c|c|c|c|c|c|c|}
\hline 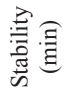 & $\begin{array}{l}\infty \\
\infty \\
\infty \\
\infty\end{array}$ & $\begin{array}{l}\infty \\
\infty \\
\sigma\end{array}$ & $\stackrel{\infty}{\stackrel{\infty}{0}}$ & $\stackrel{n}{n}$ & 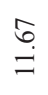 & $\begin{array}{l}n \\
n \\
?\end{array}$ & $\begin{array}{l}\infty \\
\stackrel{0}{0} \\
0\end{array}$ & $\stackrel{\infty}{\rightrightarrows}$ & $\begin{array}{l}\infty \\
= \\
=\end{array}$ & $\begin{array}{l}\text { กิ } \\
\varrho\end{array}$ & $\begin{array}{l}\infty \\
= \\
=\end{array}$ & $\stackrel{\infty}{\stackrel{\sim}{I}}$ & 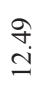 \\
\hline$r$ & $\begin{array}{l}0 \\
\mathscr{\infty} \\
\stackrel{0}{\varphi}\end{array}$ & 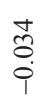 & $\begin{array}{l}\stackrel{\Delta}{0} \\
\stackrel{0}{\varphi}\end{array}$ & $\begin{array}{l}\bar{\sigma} \\
\ddot{\varphi}\end{array}$ & $\begin{array}{l}\infty \\
\stackrel{8}{8} \\
\stackrel{\varphi}{\varphi}\end{array}$ & $\begin{array}{l}\text { ț } \\
\stackrel{0}{0} \\
\dot{\varphi}\end{array}$ & $\begin{array}{l}\stackrel{J}{\Delta} \\
\stackrel{0}{\oplus}\end{array}$ & $\begin{array}{l}\stackrel{a}{0} \\
\stackrel{0}{9}\end{array}$ & $\begin{array}{l}0 \\
0 \\
0 \\
\end{array}$ & $\begin{array}{l}\frac{1}{\Delta} \\
\stackrel{1}{0}\end{array}$ & 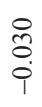 & $\begin{array}{l}\overrightarrow{0} \\
\stackrel{\varphi}{0}\end{array}$ & 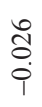 \\
\hline$\infty$ & $\begin{array}{l}\infty \\
\stackrel{\sim}{\sim} \\
0\end{array}$ & 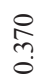 & $\begin{array}{l}\stackrel{2}{0} \\
\text { ڤె }\end{array}$ & 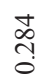 & 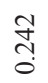 & 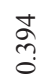 & 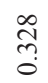 & $\frac{\Delta}{m}$ & $\begin{array}{l}\text { రి } \\
\text { ô }\end{array}$ & $\begin{array}{l}\text { in } \\
\stackrel{7}{0}\end{array}$ & 导 & 祍 & 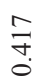 \\
\hline ه & $\begin{array}{l}\stackrel{0}{0} \\
\stackrel{0}{\varphi} \\
\stackrel{9}{1}\end{array}$ & $\begin{array}{l}\stackrel{+}{d} \\
\stackrel{1}{\oplus}\end{array}$ & $\begin{array}{l}0 \\
\stackrel{0}{0} \\
\stackrel{9}{\varphi}\end{array}$ & $\begin{array}{l}\infty \\
\stackrel{0}{0} \\
\stackrel{\varphi}{\varphi}\end{array}$ & 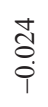 & $\begin{array}{l}\text { ô } \\
\stackrel{0}{\oplus}\end{array}$ & 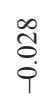 & $\begin{array}{l}\text { tr } \\
\stackrel{2}{0} \\
\stackrel{\varphi}{i}\end{array}$ & $\begin{array}{l}\hat{8} \\
\stackrel{0}{9}\end{array}$ & $\begin{array}{l}\stackrel{q}{0} \\
\stackrel{0}{9}\end{array}$ & 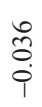 & $\begin{array}{l}\stackrel{0}{\circ} \\
\dot{9}\end{array}$ & $\begin{array}{l}\infty \\
\stackrel{\infty}{0} \\
\stackrel{1}{\varphi}\end{array}$ \\
\hline 3 & $\begin{array}{l}\infty \\
\infty \\
i\end{array}$ & 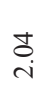 & $\stackrel{n}{\stackrel{n}{=}}$ & $\stackrel{0}{\circ}$ & $\stackrel{n}{n}$ & त् & $\underset{-\infty}{\infty}$ & $\stackrel{\nabla}{\stackrel{\Xi}{ت}}$ & & $\stackrel{\circ}{i}$ & $\vec{\sigma}$ & $\stackrel{\infty}{\infty}$ & $\stackrel{\mathbb{Z}}{\stackrel{\mathrm{S}}{2}}$ \\
\hline オ & $\stackrel{\leftrightarrow}{\varrho}$ & $\stackrel{\text { q }}{-}$ & $\vec{ָ}$ & กี & $\stackrel{n}{n}$ & & $\stackrel{\text { mे }}{-}$ & $\stackrel{\infty}{\stackrel{\infty}{\circ}}$ & $\stackrel{\leftrightarrow}{\sigma}$ & $\underset{-}{\infty}$ & $\stackrel{?}{\stackrel{f}{-}}$ & $\stackrel{\infty}{\infty}$ & $\stackrel{\overbrace ָ}{i}$ \\
\hline$\tilde{3}$ & $\begin{array}{l}\stackrel{8}{0} \\
\text { i }\end{array}$ & $\stackrel{\varrho}{\sigma}$ & $\stackrel{\text { I }}{-}$ & ?ִ & $\stackrel{\overbrace{}}{-}$ & $\begin{array}{l}\infty \\
\stackrel{\infty}{i}\end{array}$ & $\stackrel{\infty}{\stackrel{\infty}{.}}$ & $\hat{n}$ & $\stackrel{\text { m? }}{\rightarrow}$ & तె & nุ? & $\stackrel{\Xi}{\rightarrow}$ & กै? \\
\hline$\tilde{U}$ & $\stackrel{\vec{\sigma}}{\circ}$ & 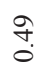 & $\stackrel{n}{\stackrel{n}{0}}$ & $\stackrel{+}{n}$ & $\tilde{n}$ & 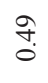 & $\stackrel{n}{\circ}$ & $\hat{n}$ & กุ. & $\begin{array}{l}\text { ?ִ } \\
?\end{array}$ & $\tilde{n}$ & $\stackrel{3}{0}$ & $\begin{array}{l}\infty \\
0 \\
0\end{array}$ \\
\hline$\vec{U}$ & $\stackrel{\varrho}{\leftrightarrows}$ & $\stackrel{\simeq}{\leftrightarrows}$ & $\stackrel{m}{\rightleftarrows}$ & $\stackrel{m}{=}$ & $\exists$ & $\exists$ & $\stackrel{8}{\circ}$ & 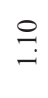 & $\exists$ & $\stackrel{ }{=}$ & $\stackrel{0}{0}$ & $\stackrel{0}{=}$ & $\stackrel{g}{\circ}$ \\
\hline 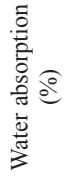 & $\stackrel{n}{6}$ & $\begin{array}{l}n \\
\infty \\
\infty\end{array}$ & ֶֶ. & $\hat{6}$ & $\tilde{6}$ & in & $\begin{array}{l}n \\
\stackrel{n}{n} \\
n\end{array}$ & $\stackrel{0}{\dot{b}}$ & \begin{tabular}{l}
0 \\
\multirow{6}{0}{}
\end{tabular} & in & $\ddot{b}$ & ت্ & $\overrightarrow{8}$ \\
\hline 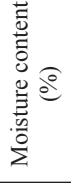 & $\hat{\varrho}$ & $\stackrel{\mathfrak{M}}{\mathrm{I}}$ & $\simeq$ & $\simeq$ & $\stackrel{\Xi}{=}$ & $\Xi$ & 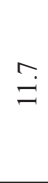 & $\stackrel{+}{=}$ & $\stackrel{n}{=}$ & $\stackrel{\circ}{\circ}$ & $=$ & $=$ & $\stackrel{\text { ִ }}{=}$ \\
\hline 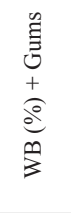 & 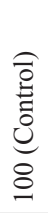 & 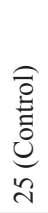 & $\begin{array}{l}0 \\
\underset{4}{+} \\
\sim \\
\sim\end{array}$ & $\begin{array}{l}0 \\
\vdots \\
⿱ \\
\sim \\
\sim\end{array}$ & $\begin{array}{l}0 \\
\rtimes \\
+ \\
\end{array}$ & $\begin{array}{l}\widehat{0} \\
\text { 咅 } \\
\text { 它 } \\
\text { in }\end{array}$ & \begin{tabular}{l}
0 \\
\multirow{4}{1}{} \\
+ \\
0 \\
$n$
\end{tabular} & $\begin{array}{l}0 \\
0 \\
\pm \\
\text { in }\end{array}$ & 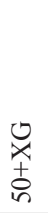 & 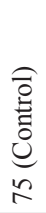 & 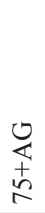 & 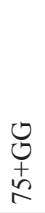 & $\begin{array}{l}0 \\
x \\
+ \\
⿱ \\
r\end{array}$ \\
\hline
\end{tabular}




\section{Results}

\section{Effects of hydrocolloids on SRC values of whole-barley fortified flour}

The effect of three gums on SRC profiles of whole-barley fortified flour blends is shown in Table S1*. The W-SRC, LA-SRC, SC-SRC, and Suc-SRC values decreased slightly with the increased addition levels of arabic gum. While, the W-SRC, LA-SRC, SC-SRC, and Suc-SRC values of whole-barley fortified flour blends were positively correlated with the amount of whole-barley flour, guar gum, and xanthan gum. Moreover, the guar gum and xanthan gum had a similar impact on the SRC values of whole-barley fortified flour, which was in agreement with the previous report ( $\mathrm{Li}$ et al. 2013). The water absorption of wheat flour was increased and dough rheological properties were affected by the presence of guar gum or xanthan gum.

\section{Effects of hydrocolloids on the alveograph values of whole-barley fortified dough}

In our study, the alveograph values of whole-barley fortified flour blends with different addition levels $(0.5 \%, 1.0 \%$, and $2.0 \%)$ of hydrocolloids (arabic gum, guar gum and xanthan gum) were determined to observe the effect of hydrocolloids on the rheological properties of whole-barley fortified dough. In Table S2, the alveograph P and P/L values of whole-barley fortified dough increased and the $\mathrm{L}$ and $\mathrm{W}$ values decreased with the increased addition levels of whole-barley flour. Moreover, the alveograph L values of barley-fortified dough increased, while $\mathrm{P}, \mathrm{W}$ and $\mathrm{P} / \mathrm{L}$ values reduced with the addition of arabic gum. Guar gum and xanthan gum had opposite results on rheological properties of whole-barley fortified dough as that of arabic gum. Meanwhile, similar impacts on the alveograph values of whole-barley fortified flour were also found between guar gum and xanthan gum. The $\mathrm{P}$ and $\mathrm{P} / \mathrm{L}$ values of whole-barley fortified dough increased but $\mathrm{L}$ and $\mathrm{W}$ values decreased with the addition of guar gum or xanthan gum (Table 1).

\section{Effects of hydrocolloids on Mixolab parameters of whole-barley fortified cracker dough}

In order to observe the effects of individual hydrocolloids on whole-barley fortified dough behaviors during mixing and baking, the combined effects of dual mixing and temperature constraints on dough was conducted at the same time using a Mixolab. The Mixolab measures the torque $(\mathrm{Nm})$ produced by mixing the dough between two kneading arms in real time along with a dual mixing and temperature constraints. A complete thermo-mechanical characterization of flour and physicochemical behavior of the dough, including water absorption, dough mixing property, protein weakening effect, starch gelatinization and retrogradation characteristics, and enzymatic activity such as proteases and amylases can be obtained from the Mixolab (Rosell et al. 2007). Results of Mixolab measurements indicated that arabic gum reduced the water absorption of barley-fortified flour blends, while guar gum or xanthan gum induced a significant increase in water absorption, al-

*Further details about the Electronic Supplementary Material (ESM) can be found at the end of the article. 
though the guar gum had a less extent of water absorption than xanthan gum (Table 1). Besides, the protein weakening, starch gelatinization, and enzyme activity were suffered different influences by the involved arabic gum, guar gum, and xanthan gum during the thermo-mechanical effect.

\section{Discussion}

In our previous study, the water absorption of whole wheat flour was reduced (reduced SRC values) by involved arabic gum ( $\mathrm{Li}$ et al. 2013). The water absorption of wholebarley fortified flour blends was also reduced by the presence of arabic gum. However, the W-SRC, LA-SRC, SC-SRC, and Suc-SRC were increased by involved guar gum and xanthan gum, especially the xanthan gum had an intrinsically higher water absorption capacity than either arabic gum or guar gum. The different helical and linear molecule structures of guar gum and xanthan gum were the decisive factor to cause their variation of water absorption capacity (Rosell et al. 2001; Rosell et al. 2007).

In the real-world practice, a good-quality cracker flour would require low $\mathrm{P}$ value and high $\mathrm{W}$ value; on the other hand, a poor-quality cracker flour is usually too strong (P value too high) and less extensible (L value too low) (Slade et al. 1994). Comparing the effectiveness of arabic gum, guar gum, and xanthan gum on alveograph values of wholebarley fortified dough, arabic gum yielded better results by reducing the $\mathrm{P}$ value and increasing the L value of dough. Therefore, the arabic gum can offset the negative outcomes of adding whole-barley flour in the dough. Our previous study reported that the wholewheat dough hardness can be softened by the arabic gum (Li et al. 2013). Firstly, arabic gum has a branched but compact structure that could promote the interaction between arabic gum polar groups and the peptide chains of the gluten-forming proteins, leading to increased dough extensibility (Bárcenasb et al. 2009). Secondly, arabic gum might interact with gliadin to form lamellar liquid-crystalline phases in water, which may contribute to dough extensibility allowing gas cell to expand and result in an increased volume of bakery products (Tamstorf et al. 1986). While, barley-fortified dough was stiffened and its tenacity (which is correlated with $\mathrm{P}$ value) increased by the addition of guar gum or xanthan gum during dough mixing. And this phenomenon might be due to the increased viscosity of doughs with the presence of guar gum and xanthan gum. Furthermore, the xanthan gum had more observable effects not only on water absorption but also on alveograph properties than guar gum. Xanthan molecules solution form intermolecular aggregates through hydrogen bonding and polymer entanglements. Xanthan gum showed a greater impact on increasing the $\mathrm{P}$ value and decreasing the $\mathrm{L}$ value of barley-fortified dough than arabic gum or guar gum did, which was detrimental to the cracker baking quality. These different functions of hydrocolloids might be due to their variation in molecule structures. For example, highly compact and branched structure of arabic gum and linear structure of guar gum and xanthan gum make them have the distinct physicochemical and rheological properties. Rojas et al. (1999) noted that the effects of hydrocolloids on mechanical and baking properties largely depended on the nature of the added polymers and their molecular weight. Besides, the reduced $\mathrm{W}$ value indicated the weakening 
gluten strength of barley-fortified cracker dough. In addition, it was noticed that the whole-barley fortified dough was sticky and stiff, which might be due to the high water absorption capacity of $\beta$-glucan.

In the Mixolab test, the barley-fortified cracker dough was mixed to achieve $1.1 \mathrm{Nm}$ torque $(\mathrm{C} 1)$. As the dough temperature increased to $90{ }^{\circ} \mathrm{C}$, the dough was subjected to a combined effect of kneading and thermo-destruction. The gluten network was weakened caused by the thermo-mechanical effect during the heating period. The protein weakening (C2) of barley-fortified dough was reduced with the addition of arabic gum, which might be due to the formation of hydrophilic complexes with gluten proteins. Arabic gum was likely to bind the exterior hydrophobic surface of gluten macropolymers and promoted the aggregation of gluten proteins. Also, the ability to form gum-gluten complexes appeared to be related to the density of the anionic groups in hydrocolloids (Ribotta et al. 2005). The water absorption was reduced and more water was redistributed to gluten proteins triggered by involved arabic gum to form a stronger network in barley-fortified dough system, which might have a positive effect during the protein unfolding and delay the rate of protein weakening $(\alpha)$. On the contrary, guar gum or xanthan gum solution is a non-Newtonian fluid and will become thinning under shearing action during dough mixing. Linear molecules of guar gum and xanthan gum have a much larger hydrodynamic volume for interacting with water molecules. The guar gum or xanthan gum might compete with gluten proteins for water, which restrained the gluten development in whole barley-fortified dough system. This effect facilitated the protein weakening (C2) and destroyed the oven spring and breaking strength of barley-fortified crackers.

Further protein destabilization during heating might be masked by greater changes of physicochemical properties of starch granules. Protein denaturation and unfolding facilitated the exposure of hydrophobic groups in gluten proteins and promote the hydrophobic interactions among them (Voutsinas et al. 1983); as a result, the water absorption and gelatinization of starch granules were enhanced. Mixolab results showed that $\mathrm{C} 3$ and starch gelatinization rate $(\beta)$ were reduced by the involved arabic gum, guar gum, or xanthan gum. However, a significant increase in the peak torque was observed as the wholebarley flour was added. This might be explained by the fact that the hydrocolloids have high-level water absorption capacity. For example, the helical and linear structures of guar gum or xanthan gum were prone to absorb water to form gum gels, which might be responsible for the growth of the torque during heating.

The enhancement of torque continues until the linkages among starch molecules which formed in heating stage were broken by the amylases and other enzymes. Additionally, the starch gels were sheared thinning during persistent mixing, which caused a reduction of viscosity. The stability of the starch gels (increased $\mathrm{C} 4$ value) was increased by the presence of guar gum or xanthan gum during cooling period, which normally attributed to the alleviating and protective effect of gums from mechanical shear. Furthermore, xanthan gum played a more dramatic role in preventing dough system from shearing (increased C4 value) which might be due to its high denseness. With the temperature steadily decline, the starch retrogradation progressively happened. The starch retrogradation rate $(\gamma)$ was increased by the inclusion of whole-barley flour during the very early stage 
of cooling. However, starch retrogradation was reduced by the incorporation of arabic gum, guar gum, or xanthan gum (reduced C5 value). In addition, xanthan gum had a greater function in reducing the starch retrogradation. The most likely reason was that the high-level water holding properties of gums restricted the mobility of starch gels (especially the amylose) to cross-link during retrogradation. Last but not the least, Collar (2003) reported that the staling kinetics of bread had a highly significant correlation with the pasting behavior of the dough. Therefore, starch retrogradation properties was likely to depend on the gelatinization properties in various doughs system.

\section{Acknowledgements}

This research was supported by the National Natural Science Funds of China (31501407) and China Postdoctoral Science Foundation (2014M560393).

\section{References}

Bárcenasb, M.E., De la O-Kellerb, J., Rosella, C.M. 2009. Influence of different hydrocolloids on major wheat dough components (gluten and starch). J. Food Engineering 94:241-247.

Collar, C. 2003. Significance of viscosity profile of pasted and gelled formulated wheat doughs on bread staling. Eur. Food Res. and Technol. 216:505-513.

Izydorczyk, M.S., Macri, L.J., MacGregor, A.W. 1998. Structure and physicochemical properties of barley non-starch polysaccharides - I. Water-extractable $\beta$-glucans and arabinoxylans. Carbohydrate Polymers 35:249-258.

Kweon, M., Slade, L., Levine, H. 2011. Solvent retention capacity (SRC) testing of wheat flour: Principles and value in predicting flour functionality in different wheat-based food processes and in wheat breeding A review. Cereal Chem. 88:537-552.

Li, J., Hou, G.G., Chen, Z.X., Gehring, K. 2013. Effects of endoxylanases, vital wheat gluten, and gum Arabic on the rheological properties, water mobility, and baking quality of whole-wheat saltine cracker dough. J. Cereal Sci. 58:437-445.

Li, J., Hou, G.G., Chen, Z.X., Chung, A.L., Gehring, K. 2014. Studying the effects of whole-wheat flour on the rheological properties and the quality attributes of whole-wheat saltine cracker using the SRC, alveograph, rheometer, and NMR technique. LWT-Food Sci. and Technol. 55:43-50.

Rojas, J.A., Rosell, C.M., Benedito de Barber, C. 1999. Pasting properties of different wheat flour-hydrocolloid systems. Food Hydrocolloids 13:27-33.

Rosell, C.M., Rojas, J.A., Benedito de Barber, C. 2001. Influence of hydrocolloids on dough rheology and bread quality. Food Hydrocolloids 15:75-81.

Rosell, C.M., Collar, C., Haros, M. 2007. Assessment of hydrocolloid effects on the thermo-mechanical properties of wheat using the Mixolab. Food Hydrocolloids 21:452-462.

Ribotta, P.D., Ausar, S.F., Beltramo, D.M., León, A.E. 2005. Interactions of hydrocolloids and sonicated-gluten proteins. Food Hydrocolloids 19:93-99.

Slade, L., Levine, H., Craig, S., Arciszewski, H. 1994. Reducing checking in crackers with pentosanase. United States Patent 5362502 .

Slavin, J., Jacobs, D., Marquardt, L. 2000. Grain processing and nutrition. Critical Reviews in Food Sci. and Nutr. 4:309-326.

Stoenescu, G., Ionescu, V., Vasilean, I., Aprodu, I., Banu, I. 2010. Prediction the quality of industrial flour using the Mixolab device. Bull. of University of Agric. Sci. and Veterinary Medicine Agric. 67:429-434.

Tamstorf, S., Jonsson, T., Krog, N. 1986. The role of fats and emulsifiers in baked products. Chemistry and physics of baking. The Royal Society of Chemistry. Bristol, UK. pp. 75-88.

Voutsinas, L.P., Cheung, E., Nakai, S. 1983. Relationships of hydrophobicity to emulsifying properties of heat denatured proteins. J. Food Sci. 48:26-32. 


\section{Electronic Supplementary Material (ESM)}

Electronic Supplementary Material (ESM) associated with this article can be found at the website of CRC at http://www.akademiai.com/content/120427/

Electronic Supplementary Table S1. Solvent retention capacity profiles of whole-barley fortified cracker flour blended with gums

Electronic Supplementary Table S2. Alveograph values of whole-barley fortified flour blended with gums 